Revista Brasileira de Agricultura Irrigada v.8, nº 3, p.280 - 295, 2014

ISSN 1982-7679 (On-line)

Fortaleza, CE, INOVAGRI - http://www.inovagri.org.br

DOI: $10.7127 /$ rbai.v8n300212

Protocolo 212/14 - 15/01/2013 Aprovado em 28/04/2014

\title{
QUALIDADE INDUSTRIAL DA CANA-DE-AÇÚCAR FERTIRRIGADA SOB DIFERENTES LÂMINAS DE ÁGUA NO SUDOESTE GOIANO
}

\author{
Nelmício Furtado da Silva ${ }^{1}$, Lígia Campos de Moura ${ }^{2}$, Fernando Nobre Cunha ${ }^{3}$, Pedro \\ Henrique Ribeiro ${ }^{4}$, José Joaquim Carvalho ${ }^{5}$ Marconi Batista Teixeira ${ }^{6}$
}

\begin{abstract}
RESUMO
Objetivou-se com o presente trabalho avaliar as características industriais e o rendimento da cana-de-açúcar sob influência de diferentes lâminas de irrigação com e sem efeito da fertirrigação com $\mathrm{N}$ e K. O material vegetal foi obtido por corte manual, a partir de uma área cultivada com a variedade RB 85-5453, no Instituto Federal Goiano - Câmpus Rio Verde - GO. O delineamento experimental utilizado foi o de blocos ao acaso, analisado em esquema fatorial $5 \times 2$, com quatro repetições. Os tratamentos consistiram em cinco níveis de reposição hídrica $(100,75,50,25$ e $0 \%$ de umidade do solo na capacidade de campo) combinados sem e com aplicação de $\mathrm{N}$ e $\mathrm{K}$ via água de irrigação (fertirrigação). Para a determinações dos parâmetros industriais da cana-de-açúcar foram coletadas 10 colmos de cada repetição, colhidos aos 385 dias de desenvolvimento das plantas. Foram analisados os parâmetros tecnológicos mais utilizados para estimar a qualidade da matéria-prima. Houve incrementos no rendimento de açúcar e álcool de 34,48\% e $12,43 \%$ na lâmina de $75 \%$ fertirrigada quando comparado respectivamente ao menor incremento ocorrido em $0 \%$ e ao maior rendimento ocorrido na lâmina de $75 \%$ somente irrigada.
\end{abstract}

Palavras-chave: rendimento, qualidade, matéria-prima, reposição hídrica, adubação.

\section{INDUSTRIAL QUALITY OF SUGAR CANE FERTIRRIGATED UNDER DIFFERENT BLADES OF WATER IN SOUTHWEST GOIANO}

\footnotetext{
${ }^{1}$ Mestrando em Ciências Agrárias - Agronomia, Instituto Federal Goiano - Câmpus Rio Verde, Rodovia Sul Goiana, Km 01, CEP: 75.901-170, Rio Verde - GO, e-mail: nelmiciofurtado@ gmail.com

${ }^{2}$ Graduanda em Eng. de Alimentos, IFGoiano - Câmpus Rio Verde, e-mail: ligialirios@ hotmail.com

${ }^{3}$ Mestrando em Ciências Agrárias - Agronomia, IFGoiano - Câmpus Rio Verde, e-mail: fernandonobrecunha@hotmail.com

${ }^{4}$ Mestre em Irrigação, Universidade Federal de Campina Grande - Campina Grande - PB, e-mail: pedroirri@gmail.com

${ }^{5}$ Pós-doutorando em Ciências Agrárias - Agronomia, IFGoiano - Câmpus Rio Verde, e-mail: josejoaquimcarvalho@yahoo.com.br

${ }^{6}$ Eng. Agrônomo, Prof. Dr. em Agronomia, IFGoiano - Câmpus Rio Verde, e-mail: marconibt@gmail.com
} 


\begin{abstract}
This work aimed to evaluate the industrial characteristics and the yield of sugar cane under the influence of different blades of irrigation with and without effect of fertirrigation with $\mathrm{N}$ and $\mathrm{K}$. The plant material was obtained by manual cutting, from a cultivated area with the variety RB 85-5453, Federal Institute Goiano-Campus Rio Verde - GO. The experimental design used randomized blocks, a fully randomized $5 \times 2$ factorial design was used, with four repetitions The treatments consisted of five levels of hydration (100, 75, 50, 25 and $0 \%$ of soil moisture at field capacity) combined with and without application of $\mathrm{N}$ and $\mathrm{K}$ way irrigation water (fertirrigation). For determination of the parameters industrial of sugar cane were collected 10 stalks of each repetition, harvested 385 days of plant development. The following technological parameters more used were analyzed to estimate the quality raw material. There were increased the yield of sugar and alcohol of $34,48 \%$ and 12 , $43 \%$ in blade of $75 \%$ fertirrigated, when compared to smaller increment occurred in $0 \%$ and the highest yield occurred under the blade of $75 \%$ only irrigated.
\end{abstract}

Keywords: yield, quality, raw, fluid replacement, fertilization.

\section{INTRODUÇÃO}

A cana-de-açúcar é, em si, uma usina de enorme eficiência, uma vez que cada tonelada tem um potencial energético equivalente ao de 1,2 barril de petróleo. O Brasil é o maior produtor do mundo, seguido da Índia e Austrália. Na média, 55\% da cana-de-açúcar brasileira se transformam em álcool e $45 \%$ em açúcar. No país se planta cana-de-açúcar no Centro-Sul e no Norte-Nordeste, o que permite dois períodos de safra (UNICA, 2004). A biomassa contribui com $15,7 \%$ da composição da matriz energética brasileira (EPE, 2012). Essa grande demanda por bioenergia contribui para que a cana-de-açúcar
(Saccharum officinarum L.) ser uma das principais culturas do Brasil.

Segundo Frasson (2007) a expansão do mercado mundial de açúcar e álcool tem estimulado o aumento do investimento no setor em todo o país.

Dessa forma, além das necessidades de alta produção de cana-de-açúcar por hectare, há um interesse maior, que é a alta produção de sacarose. A indústria sucroalcooleira visa à recuperação máxima da sacarose da cana-deaçúcar ao menor custo possível. A qualidade da matéria-prima da cana-de-açúcar a ser processada é de fundamental importância para se conseguir atingir esse objetivo. A qualidade da 
cana-de-açúcar é a concentração total de açúcares (sacarose e açúcares redutores), recuperáveis no processo industrial e expressa em quilograma por tonelada de cana. A qualidade industrial da cana-de-açúcar irrigada e fertirrigada com $\mathrm{N}$ e $\mathrm{K}$ foi, e está sendo estudada no Brasil por diversos autores, dentre eles, temos Carvalho et al. (2008), Dalri et al. (2008), Silva et al. (2009) e Farias et al. (2009), Gouveia Neto (2012).

Porém, vários fatores podem interferir na qualidade final da matéria-prima. $\mathrm{O}$ rendimento e a produção de açúcar e de álcool da cana-deaçúcar irrigada dependem da quantidade de água aplicada, do manejo de irrigação combinado com a quantidade certa de adubação, da variedade, da idade do corte, do tipo de solo e do clima. O valor da cana-de-açúcar se baseia no chamado Açúcar Total Recuperável (ATR), que corresponde à quantidade de açúcar disponível na matéria-prima subtraída das perdas no processo industrial, e nos preços do açúcar e etanol vendidos pelas usinas nos mercados interno e externo (CONSECANA, 2006).

Um fator significativo que deve ser destacado visto que influencia na produtividade das culturas, é a disponibilidade de água e de nutrientes. Com relação à água, nem sempre as chuvas atendem à real necessidade hídrica das plantas; surge, daí a importância da irrigação a qual, quando bem planejada tem retorno econômico inquestionável (DANTAS NETO et al., 2006).

Dessa forma, objetivou-se com o presente trabalho avaliar as características industriais e o rendimento bruto de açúcar e álcool da canade-açúcar sob influência de diferentes lâminas de irrigação com e sem efeito da fertirrigação com $\mathrm{N}$ e $\mathrm{K}$.combinados, no sudoeste do estado de Goiás.

\section{MATERIAL E MÉTODOS}

O material vegetal foi obtido por corte manual, a partir de uma área cultivada com a variedade RB 85-5453, que apresenta como características principais alto teor de açúcar e precocidade, no Instituto Federal Goiano Câmpus Rio Verde - GO, nas condições de cana planta, com plantio em março de 2011, localizada na latitude $17^{\circ} 48^{\prime} 28^{\prime \prime} \mathrm{S}$ e longitude $50^{\circ} 53$ '57” O, com altitude média de 720 metros e relevo suave ondulado ( $6 \%$ de declividade). $\mathrm{O}$ clima da região foi classificado conforme Köppen, como Aw (tropical), com precipitação nos meses de outubro a maio, e com seca nos meses de junho a setembro. A partir dos dados climatológicos do período experimental, foi elaborada a estimativa do balanço hídrico decendial para a cana-de-açúcar em manejo de sequeiro, sendo que a Evapotranspiração de 
Referência $\left(\mathrm{Et}_{0}\right)$ foi calculada segundo a equação de Penman-Monteith (MONTHEITH, 1973) (Figura 1).

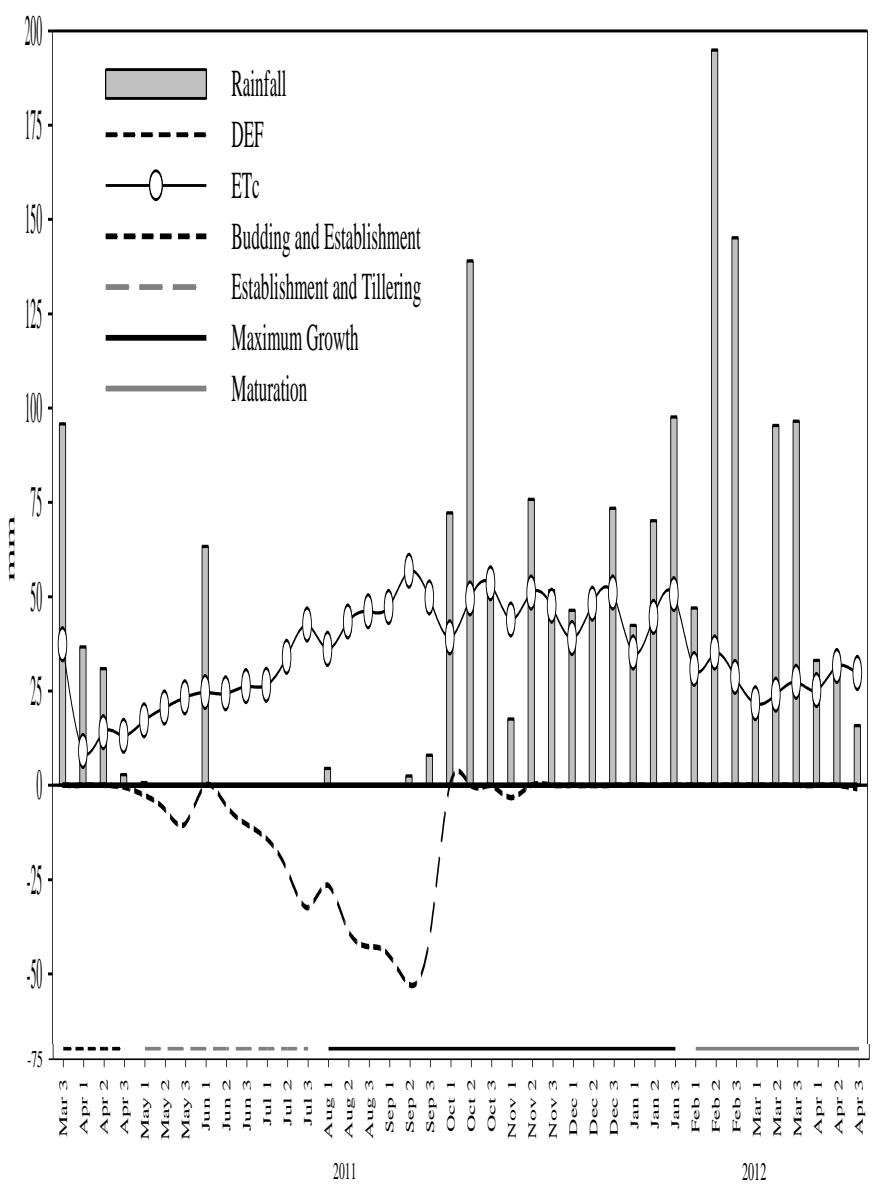

Figura 1. Balanço hídrico decendial do município de Rio Verde no período decorrente do experimento. Fonte: Estação Normal INMET - Rio Verde - GO.

As parcelas experimentais, constituídas de três sulcos de linha com espaçamento de 1,80 $\mathrm{x} \quad 0,4 \mathrm{~m}$ entre as linhas e entre linhas duplas e $8 \mathrm{~m}$ de comprimento, totalizando $35,2 \mathrm{~m}^{2}$ de área total por parcela. O solo da área experimental foi classificado como Latossolo Vermelho distroférrico (LVdf), fase cerrado, de textura média (Embrapa, 2006) e as características químicas desse solo encontram-se na (Tabela 1).

Tabela 1. Características químicas do Latossolo Vermelho distroférrico, nas camadas de $0-20$ e $20-40 \mathrm{~cm}$ de profundidade, antes da implantação do experimento.

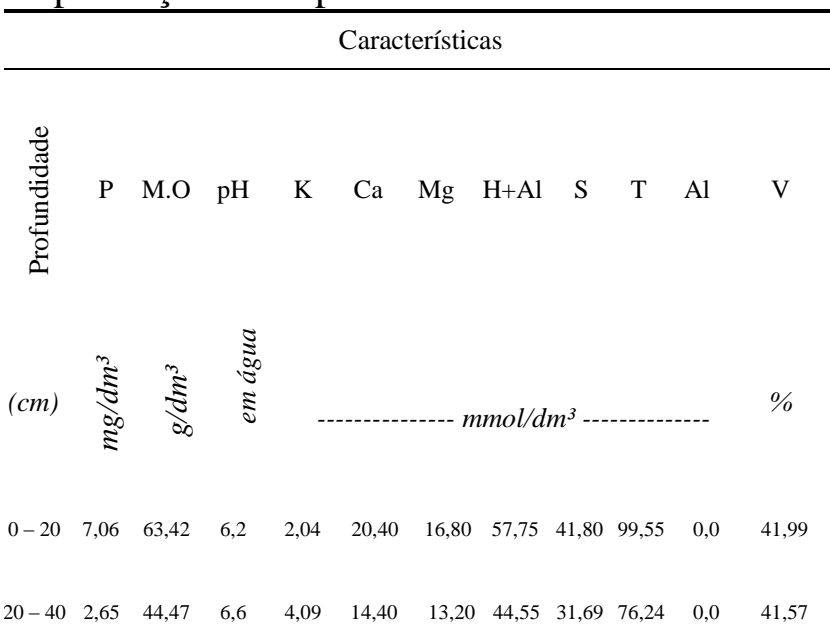

pH em água destilada, $\mathrm{g} / 100 \mathrm{~cm}^{3}$ de terra. Extrator de $\mathrm{P}, \mathrm{K}$ e micronutrientes, Mehlich-1. M.O Matéria Orgânica, $\mathrm{g} / \mathrm{dm}^{3}$. T Capacidade de troca de cátions, $\mathrm{S}+\mathrm{H}+\mathrm{Al}$. V Porcentagem de saturação de bases, V=100 S/T.

O delineamento experimental utilizado foi o de blocos ao acaso, analisado em esquema fatorial 5 x 2, com quatro repetições. Os tratamentos consistiram em cinco lâminas de reposição hídrica $(0,25,50,75$ e 100\% de reposição hídrica) combinados sem e com aplicação de fertilizante nitrogenada e potássica via água de irrigação (fertirrigação) sendo todas as parcelas dos tratamentos foram adubadas com adubação de base no sulco de plantio, segundo recomendações de Sousa e Lobato (2004). Todos os tratamentos receberam $100 \mathrm{~kg} \mathrm{ha}^{-1}$ de $\mathrm{N}$ - uréia, $120 \mathrm{~kg} \mathrm{ha}^{-1}$ de $\mathrm{P}_{2} \mathrm{O}_{5^{-}}$ 
super simples e $80 \mathrm{~kg} \mathrm{ha}^{-1}$ de $\mathrm{K}_{2} \mathrm{O}$-cloreto de potássio. O fertilizante fosforado foi aplicado no sulco de plantio e o nitrogênio e potássio ao longo do crescimento da cultura por meio do sistema de irrigação de forma que nas parcelas onde não foi prevista a fertirrigação receberam adubação de cobertura com $\mathrm{N}$ a lanço assim como nas fertirrigadas num total de $100 \mathrm{~kg} \mathrm{ha}^{-1}$, as parcelas previstas $0 \%$ de reposição hídrica porém com fertirrigação, esta foi realizada também via água de irrigação. A (Tabela 2), mostra como foi parcelado a fertirrigação com $\mathrm{N}$ e $\mathrm{K}$ durante o ciclo de cultivo.

Tabela 2. Porcentagem do parcelamento de fertirrigação no decorrer do cultivo.

\begin{tabular}{|c|c|c|c|c|c|c|c|c|c|c|c|c|c|}
\hline \multicolumn{14}{|c|}{ Aplicação } \\
\hline & $1^{\mathrm{a}}$ & $2^{\mathrm{a}}$ & $3^{\mathrm{a}}$ & $4^{a}$ & $5^{\mathrm{a}}$ & $6^{a}$ & $7^{\mathrm{a}}$ & $8^{\mathrm{a}}$ & $9^{a}$ & $10^{\mathrm{a}}$ & $11^{\mathrm{a}}$ & $12^{\mathrm{a}}$ & Total \\
\hline Mês & & $\mathbf{J}$ & & $\mathrm{J}$ & & & $\mathrm{S}$ & $\mathrm{O}$ & $\mathrm{N}$ & $\mathrm{D}$ & $\mathrm{J}$ & $\mathrm{F}$ & \\
\hline Potássio* & 2 & 4 & 6 & 8 & & & & & 10 & & & & 100 \\
\hline
\end{tabular}

Nitrogênio 10

*Foi utilizado Cloreto de potássio branco.

Nos tratamentos com reposição hídrica, foi utilizado o método de irrigação por gotejamento subsuperficial. O tubo gotejador foi enterrado a $0,20 \mathrm{~m}$ de profundidade da superfície do solo, no meio da linha dupla, sendo que o mesmo apresenta as seguintes características: modelo Dripnet PC 16150 com parede delgada, pressão de serviço de 1 bar, vazão nominal de $1,0 \mathrm{~L} \mathrm{~h}^{-1} \mathrm{e}$ espaçamento entre gotejadores de $0,50 \mathrm{~m}$.

As aplicações foram realizadas em concentrações iguais para todas as parcelas de forma a aplicar uma quantidade homogenia de nutrientes. A aplicação de $\mathrm{N}$ e $\mathrm{K}$ ocorreram simultaneamente a irrigação, sem a aplicação de diferentes lâminas. Foi utilizado a ureia como fonte de $\mathrm{N}$ e o cloreto de potássio branco como fonte de K. O tempo das fertirrigações eram correspondentes a 3,5 horas como forma de garantir a oferta de uma mesma quantidade de nutrientes para todos tratamentos com base em uma diluição mínima. Para injeção dos fertilizantes no sistema de irrigação optou-se por um injetor Venturi que secionava os fertilizantes depois de dissolvidos em uma caixa reservatório com capacidade para $350 \mathrm{~L}$.

$\mathrm{Na}$ aplicação dos fertilizantes via água de irrigação, primeiramente era aplicada somente água para o equilíbrio hidráulico do sistema de irrigação, e permitir maior uniformidade de distribuição dos fertilizantes, em seguida era feito a fertirrigação e ao termino aplicava-se água para lavar o sistema de irrigação. 
A irrigação foi conduzida com base em tensiometria digital de punção com sensibilidade de $0,1 \mathrm{kPa}$, sendo as hastes tensiométricas instaladas nas profundidades de 0,20, 0,40, 0,60 e $0,80 \mathrm{~m}$ de profundidade e distâncias de 0,15 , $0,30,0,45$ e $0,60 \mathrm{~m}$ do tubo gotejador, com leitura do potencial matricial do solo $(\Psi \mathrm{m})$ registrada diariamente. Para determinar a necessidade de irrigação, utilizou-se tensão crítica de $50 \mathrm{KPa}$. As características físico-hídricas do solo foram determinadas mediante a curva de retenção de água no solo, de acordo com Van Genuchten (1980).

Foi realizado o monitoramento do Brix da cana em campo, nas três últimas semanas antes da colheita. Para a determinação racional do ponto de colheita da cana, tem-se utilizado o parâmetro conhecido como Índice de Maturação (IM) determinado em campo, utilizando um refratômetro portátil, calculado a partir da divisão do Brix do ápice pelo Brix da base do colmo. Para a cana-de-açúcar, os valores de IM admitidos são: (a) menor que 0,60 para cana verde; (b) entre 0,60 e 0,85 para cana em processo de maturação; (c) entre 0,85 e 1 para cana madura; e (d) maior que 1 para cana em processo de declínio de sacarose (CESNIK \& MIOCQUE, 2004; ROSSETO, 2012).

Para a determinações dos parâmetros industriais da cana-de-açúcar foram coletadas 10 colmos de cada repetição totalizando 40 colmos inteiros por tratamento, colhidos aos 385 dias de desenvolvimento das plantas, eliminando somente o ponteiro e as folhas secas, em seguida foram encaminhados para $o$ laboratório pertencente a Usina São Francisco em Quirinópolis - GO.

Foram analisados os parâmetros tecnológicos mais utilizados para estimar a qualidade da matéria-prima produzida estão relacionados no Manual de Instruções do Conselho dos Produtores de Cana-de-Açúcar, Açúcar e Álcool do Estado de São Paulo (CONSECANA, 2006). Este manual estabelece e relaciona normas de amostragem e determinações laboratoriais da qualidade da cana-de-açúcar, entre outros parâmetros. Destacam-se: Brix (B) ou teor de sólidos solúveis por cento, em peso, de caldo; Pol da cana (PC) ou teor de sacarose aparente por cento, em peso, de cana; Açúcares redutores do caldo (AR) ou teor de açúcares redutores (glicose e frutose, oriundos da hidrólise da sacarose) por cento, em peso, de caldo; Fibra da cana (F) ou teor de material insolúvel em água, por cento, em peso, de cana; Pol do caldo (S) ou teor de sacarose aparente por cento, em peso, de caldo; Pureza aparente do caldo (Q) ou porcentagem de pol do caldo em 
relação ao brix; Açúcar total recuperável (ATR) ou teor de açúcares totais (glicose, frutose e sacarose), em quilos por tonelada de cana.

Através destes resultados, calculou-se as determinações de rendimento bruto de açúcar (RBA) em (t ha $\left.{ }^{-1}\right)$, de açúcar $\left(\mathrm{t} \mathrm{ha}^{-1}\right)$ e rendimento bruto de álcool (RBAL) em $\left(\mathrm{m}^{3}\right.$ $\mathrm{ha}^{-1}$ ), foram realizados cálculos de acordo com as seguintes fórmulas: Açúcar $(\mathrm{kg}$ açúcar $/ \mathrm{t}$ cana $)=$ Pol $\times\{1,4-(4,0 /$ Pureza aparente $)\} \times$ 0,79; $\mathrm{T}_{\text {açúcar ha }}{ }^{-1}=\mathrm{t}$ cana ha ${ }^{-1} \mathrm{x} \mathrm{kg} \mathrm{açúcar} \mathrm{ha}^{-1}$; Álcool $\left(\mathrm{m}^{3} \mathrm{ha}^{-1}\right)=\mathrm{t}$ açúcar ha ${ }^{-1}$ x $0,51 / 0,79$, onde: 0,51 = quantidade de etanol em $100 \mathrm{~kg}$ de glicose e $0,79=$ densidade do etanol.

O delineamento experimental foi em blocos casualizados, cada tratamento foi avaliado em quatro repetições. As médias foram submetidas à análise de variância e os dados obtidos foram submetidos à análise de regressão, foi utilizado o software Sisvar 5.3 (FERREIRA, 2011).

\section{RESULTADOS E DISCUSSÃO}

As variáveis analisadas responderam significativamente ao fator lâmina de irrigação e fertirrigação (N e K) assim como a interação entre os dois fatores, com um grau de confiança de a $1 \%$ de probabilidade para todas as variáveis analisadas. Estes resultados estão de acordo com trabalhos realizados por (FARIAS et al, 2009), porém estes autores não trabalharam com características como $\mathrm{AR}$, e esta pesquisa foi realizada na região do Tabuleiro Costeiro paraibano. Assim como os resultados de rendimento RBA e RBAL estão de acordo com trabalho realizado por (DANTAS NETO et al., 2006); porém estes autores variaram níveis de adubação trabalhando com cana soca. O coeficiente de variação $(\mathrm{CV})$ variou de 0,09 a $1,98 \%$ evidenciando uma boa precisão experimental para determinação das características industriais e de rendimento, corroborando com resultados encontrados por Santos et al. (2004).

$\mathrm{Na}$ (Tabela 5) estão dispostos os níveis do fator lâmina de irrigação correspondentes a 0 , $25,50,75$ e $100 \%$ de reposição hídrica dentro do fator fertirrigação (com e sem aplicação de $\mathrm{N}$ e $\mathrm{K}$ via agua de irrigação), assim como os níveis de fertirrigação dentro do fator irrigação. Observa-se que todos os níveis utilizados foram significativos nos parâmetros avaliados tanto para características industriais quanto para rendimento de açúcar e álcool, quando analisados para o desdobramento de lâminas dentro de fertirrigação e fertirrigação dentro de lâminas, apresentando resultados elevados com um baixo erro experimental, estes resultados mostram com 
maior segurança a alta correlação existente entre estes fatores.

Tabela 4. Analise de desdobramento para o fator lâmina $(0,25,75$ e $100 \%$ de reposição hídrica) dentro de fertirrigação ( $\mathrm{N}$ e $\mathrm{K}$ ) para todas as características industriais e de rendimento da cana-de-açúcar.

\begin{tabular}{|c|c|c|c|c|c|c|}
\hline \multirow{2}{*}{ Fator lâmina } & \multirow{2}{*}{ GL } & B & $\mathbf{P C}$ & $\mathbf{F}$ & $\mathbf{S}$ & $\mathbf{Q}$ \\
\hline & & \multicolumn{5}{|c|}{ Quadrados Médio } \\
\hline Lâmina & 4 & $0.7938 * *$ & $0.2888^{* * *}$ & $0.9800^{* *}$ & $0.8192 * *$ & $0.3042^{* *}$ \\
\hline Lâmina & 4 & $0.2450 * *$ & $0.4050 * *$ & $0.0200 * *$ & $0.4232 * *$ & $1.3778^{* *}$ \\
\hline Lâmina & 4 & $3.07520^{* *}$ & $2.1218 * *$ & $0.5000^{* *}$ & $3.3800 * *$ & $2.78480 * *$ \\
\hline Lâmina & 4 & $0.8978 * *$ & $1.6928 * *$ & $2 * 10^{6} * *$ & $2.1632^{* * *}$ & $11.1392 * *$ \\
\hline Lâmina & 4 & $1458^{* *}$ & $0.0072 * *$ & $0.5000^{* *}$ & $0.0072^{* *}$ & $1.7298 * *$ \\
\hline Resíduo & 27 & 0.0169 & 0.0092 & 0.00008 & 0.0121 & 0.0092 \\
\hline \multirow{2}{*}{ Fator lâmina } & \multirow{2}{*}{ GL } & ATR & AR & RBA & \multicolumn{2}{|c|}{ RBAL } \\
\hline & & \multicolumn{5}{|c|}{ Quadrados Médio } \\
\hline Lâmina & 4 & $23.9432^{* *}$ & $0.0002^{* * *}$ & $0.9458^{* *}$ & \multicolumn{2}{|c|}{ 64485.9215** } \\
\hline Lâmina & 4 & $32.9672 * *$ & $0.0008 * *$ & $0.4956 * *$ & \multicolumn{2}{|c|}{$201702.0449^{* * *}$} \\
\hline Lâmina & 4 & $177.0962^{* * *}$ & $0.0032 * *$ & $3.9130 * *$ & \multicolumn{2}{|c|}{$317527.1957 * * *$} \\
\hline Lâmina & 4 & $131.2200^{* *}$ & $0.0128 * *$ & $2.5505^{* * *}$ & \multicolumn{2}{|c|}{$268569.7392^{* * *}$} \\
\hline Lâmina & 4 & $0.3200 * *$ & $0.0018^{* * *}$ & $0.0067^{* * *}$ & \multicolumn{2}{|c|}{$1929.939^{* *}$} \\
\hline Resíduo & 27 & 2.2296 & 0.0001 & 0.0139 & \multicolumn{2}{|c|}{255.4773} \\
\hline \multirow{2}{*}{$\begin{array}{c}\text { Fator } \\
\text { fertirrigação }\end{array}$} & \multirow[b]{2}{*}{ GL } & $\mathbf{B}$ & $\mathbf{P C}$ & $\mathbf{F}$ & $\mathbf{S}$ & $\mathbf{Q}$ \\
\hline & & \multicolumn{5}{|c|}{ Quadrados Médio } \\
\hline Fertirrigação & 2 & $1.039680^{* *}$ & $01.420920^{* * *}$ & $1.627480^{* *}$ & $1.627480 * *$ & $5.328280^{* *}$ \\
\hline Fertirrigação & 2 & $0.428120^{* * *}$ & $0.817120^{* * *}$ & $0.744200^{* *}$ & $0.744200 * *$ & $5.083880 * *$ \\
\hline Resíduo & 27 & 0.0169 & 0.0092 & 0.00008 & 0.0121 & 0.0092 \\
\hline \multirow{2}{*}{$\begin{array}{c}\text { Fator } \\
\text { fertirrigação }\end{array}$} & \multirow[b]{2}{*}{ GL } & ATR & $\mathbf{A R}$ & RBA & \multicolumn{2}{|c|}{ RBAL } \\
\hline & & \multicolumn{5}{|c|}{ Quadrados Médio } \\
\hline Fertirrigação & 2 & $115.627320^{* *}$ & $0.006680^{* *}$ & $1.903193 * *$ & \multicolumn{2}{|c|}{$652875.370428^{* * *}$} \\
\hline Fertirrigação & 2 & $65.962880^{* *}$ & $0.006120^{* *}$ & $0.875146^{* * *}$ & \multicolumn{2}{|c|}{$378733.197661^{* * *}$} \\
\hline Resíduo & 27 & 2.2296 & 0.0001 & 0.0139 & \multicolumn{2}{|c|}{255.4773} \\
\hline \multicolumn{7}{|c|}{$\begin{array}{l}\text { **; * significativo a nível de } 1 \% \text { de probabilidade pelo } \\
\text { teste F. Brix (B) ou teor de sólidos solúveis por cento, em } \\
\text { peso, de caldo; Pol da cana (PC) ou teor de sacarose } \\
\text { aparente por cento, em peso, de cana; Açúcares redutores } \\
\text { do caldo (AR) ou teor de açúcares redutores (glicose e } \\
\text { frutose, oriundos da hidrólise da sacarose) por cento, em } \\
\text { peso, de caldo; Fibra da cana (F) ou teor de material } \\
\text { insolúvel em água, por cento, em peso, de cana; Pol do } \\
\text { caldo (S) ou teor de sacarose aparente por cento, em peso, } \\
\text { de caldo; Pureza aparente do caldo (Q) ou porcentagem de } \\
\text { pol do caldo em relação ao brix; Açúcar total recuperável } \\
\text { (ATR) ou teor de açúcares totais (glicose, frutose e } \\
\text { sacarose), em quilos por tonelada de cana; Rendimento } \\
\text { bruto de açúcar (RBA) e rendimento bruto de álcool } \\
\text { (RBAL). }\end{array}$} \\
\hline
\end{tabular}

Os resultados das médias para características industriais Brix, Pureza e Pol do caldo, Pol da cana, Fibra e AR da cana-de-açúcar submetida à irrigação e fertirrigação com diferentes lâminas são apresentadas na (Figura 2 e 3).

De acordo com os dados, para a variável Brix (Figura 2A), observa-se que os tratamentos tanto irrigado quanto fertirrigação, foram representados por uma equação polinomial, porém houve um maior teor na lâmina de $75 \%$ fertirrigado, apresentando um aumento de 9,43\% quando comparado a $0 \%$ fertirrigado, apesar disso ambas as equações não apresentaram um coeficiente de determinação satisfatórios.

As variáveis Pureza, Pol do caldo e Pol da cana (Figura 2B, 2C e 3A, respectivamente), também obtiveram melhores resultados na lâmina de $75 \%$ fertirrigado, apresentando um acréscimo respectivo de 38,68; 20,52 e 36,36\% quando comparados a lâmina de $0 \%$ fertirrigado.

Estes resultados foram contrários a resultados de Brix e Pol encontrados por Silva et al. (2009) que avaliaram o efeito de diferentes níveis dos nutrientes $\mathrm{N}$ mais $\mathrm{K}$, aplicados em cobertura, no rendimento e na qualidade da canade-açúcar sob irrigação suplementar, onde os níveis de adubação, estudados não influenciaram significativamente nos parâmetros tecnológicos (Brix e Pol), contudo os valores tendem a diminuir com o aumento do nível.

Quando analisa-se somente a variável lâminas sem a presença da fertirrigação, observase que os valores destas mesmas variáveis tenderam a diminuir com o aumento da lâmina, sendo 
assim os melhores resultados para Pureza e Pol do caldo observados na lâmina de $25 \%$ de reposição hídrica. É possível observar ainda que a lâmina de $50 \%$ de reposição hídrica apresentou os valores inferiores para estas mesmas variáveis.

Para variáveis como Fibra e AR, foram observados valores maiores na lâmina de $100 \%$ irrigado, correspondentes respectivamente a 71,42 e $36,36 \%$, o resultado destas duas variáveis confirmaram a menor qualidade da cana-deaçúcar apresentado na lâmina de $100 \%$, segundo Barbosa et al. (2007), existe uma associação negativa entre teor de fibras e açúcar, principalmente em variedades precoces, as quais são, em geral, mais ricas em sacarose e com teor de fibra menor.

A Fibra da cana representa o teor de material insolúvel em água, por cento, em peso, de cana, e a Açúcares redutores do caldo (AR) ou teor de açúcares redutores (glicose e frutose, oriundos da hidrólise da sacarose) por cento, em peso, de caldo, valores estes que quando elevados caracterizam uma qualidade inferior da matéria-prima, porém Firme (2007) cita que não têm sido observadas alterações na qualidade tecnológica da cana- de- açúcar à época da colheita, tais como fibra e $\mathrm{AR}$, em resposta a aportes mais elevados de N. Porém segundo Moura et al. (2009) é importante lembrar que a fibra é uma importante matéria-prima para indústria. Para Leite et al. (2009) a quantidade ideal de fibra é variável entre $12 \%$ e $13 \%$, e não compromete a quantidade disponível de bagaço para queima no início da safra.

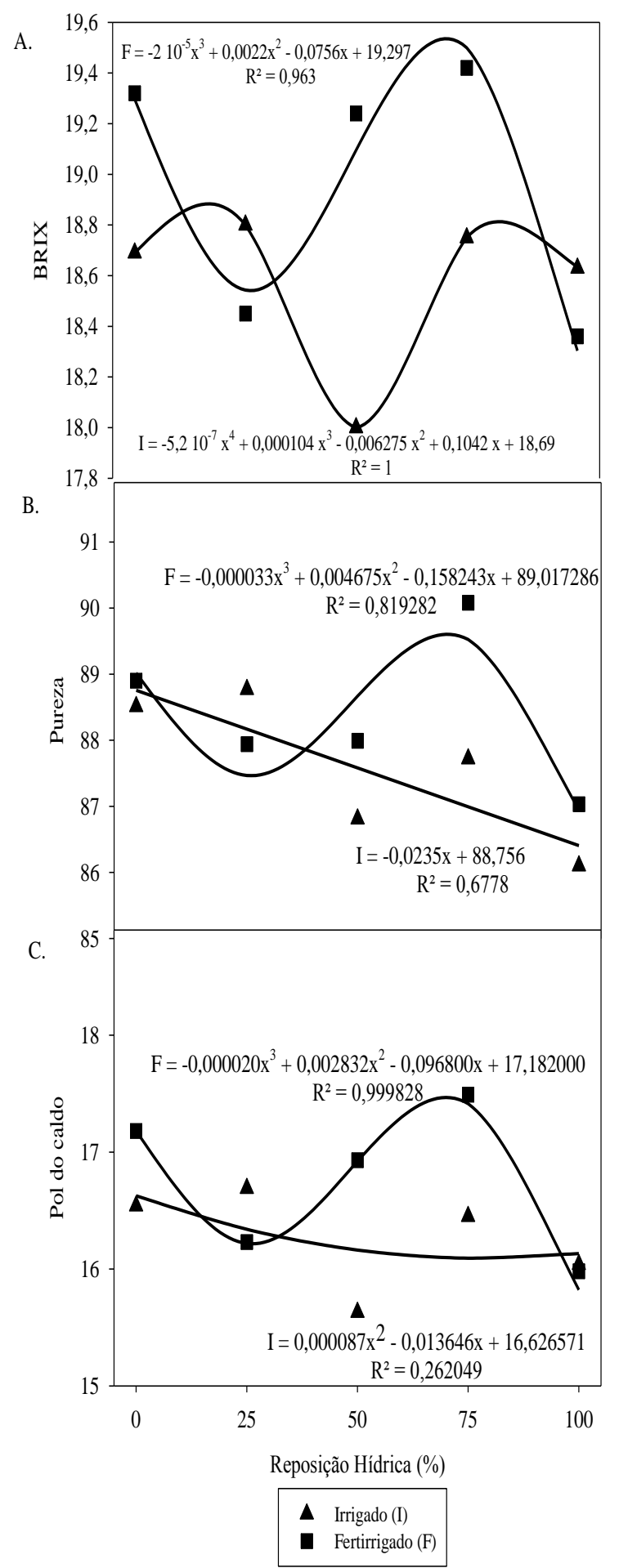

Figura 2. Características industriais (A) - Brix - B ou teor de sólidos solúveis por cento, em peso, de caldo; (B) Pureza aparente do caldo - Q ou porcentagem de pol do caldo em relação ao brix; (C) Pol do caldo $-\mathrm{S}$ ou teor de sacarose aparente por cento, em peso, de caldo da cana-de-açúcar submetida à irrigação e fertirrigação $(\mathrm{N}$ e $\mathrm{K})$ com diferentes lâminas $(0,25,50,75$ e $100 \%$ de reposição hídrica). 


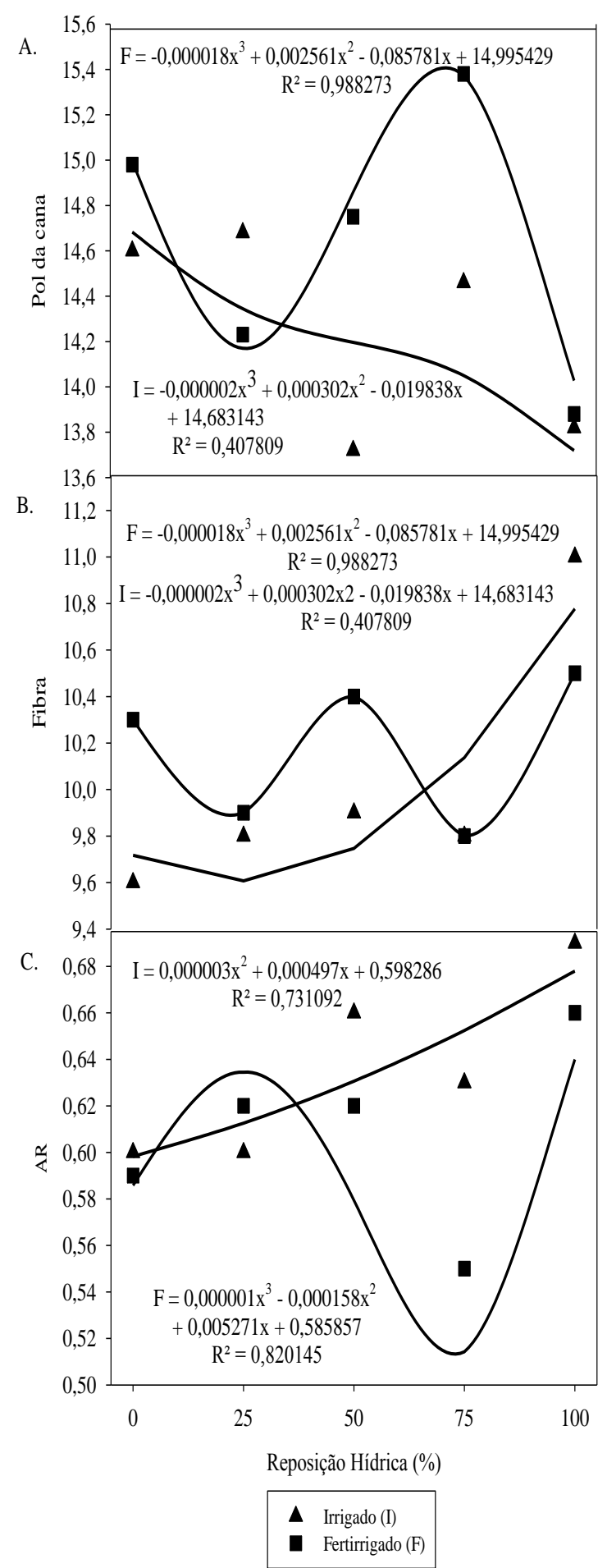

Figura 3. Características industriais (A) Pol da cana $\mathrm{PC}$ ou teor de sacarose aparente por cento, em peso, de cana; (B) Fibra da cana - F ou teor de material insolúvel em água, por cento, em peso, de cana; (C) Açúcares redutores do caldo - $\mathrm{AR}$ ou teor de açúcares redutores (glicose e frutose, oriundos da hidrólise da sacarose) por cento, em peso, de caldo da cana-de-açúcar submetida à irrigação e fertirrigação com diferentes lâminas $(0,25,50,75$ e $100 \%$ de reposição hídrica).
Os resultados das médias para característica industrial ATR da cana-de-açúcar submetida à irrigação e fertirrigação com diferentes lâminas são apresentadas na (Figura 4).

O ATR teve o seu melhor comportamento na lâmina de $75 \%$ fertirrigado, correspondendo a valores de aumento de 23,88\% e um alto coeficiente de determinação $\left(\mathrm{R}^{2}=99,08 \%\right)$. Resultados encontrados por Farias et al. (2009), encontraram melhores resultados de produção de ATR na cana irrigada com $100 \%$ da ETc, que produziu $6,74 \%$ a mais que a média das plantas irrigadas com 75 e $50 \%$ da ETc; e produziu $15,28 \%$ a mais que a cana irrigada com $25 \%$ da ETc; é de $31,35 \%$ a diferença entre a cana irrigada com a maior lâmina e a cultivada sob regime de sequeiro.

Os resultados das médias para rendimento de açúcar e álcool da cana-de-açúcar submetida à irrigação e fertirrigação com diferentes lâminas são apresentadas na (Figura 4).

Quanto ao rendimento de açúcar e álcool a lâmina de $75 \%$ com fertirrigação apresentou os melhores. De acordo com os dados, houve um crescimento polinomial quadratico com uma alta correlação $\left(\mathrm{R}^{2}=98,27 \%\right)$ tanto para o rendimento bruto de açúcar quanto para o rendimento bruto de álcool em função das lâminas de irrigação, sendo que em ambos o maior aumento aconteceu na lâmina de $75 \%$ de irrigação, com redução após para a maior lâmina de $100 \%$, este comportamento também foi observado quando se aplicou os nutrientes $\mathrm{N}$ e $\mathrm{K}$ via agua 
de irrigação (fertirrigação), estes resultados estão de acordo com Dantas Neto et al. (2006), que avaliaram a influência da adubação de cobertura $\left(\mathrm{N}\right.$ e $\mathrm{K}_{2} \mathrm{O}$ na proporção de 1 para 0,94$)$ sobre os parâmetros tecnológicos da cana-deaçúcar e 21 constataram que ocorreu aumento no rendimento bruto do açúcar, de 9,00 para 12,58 t $\mathrm{ha}^{-1}$; no rendimento de álcool esses valores foram de 6,25 e 8,91 $\mathrm{m}^{3} \mathrm{ha}^{-1}$.

Apesar do aumento no rendimento de álcool ser dependente do aumento do rendimento de açúcar, e portanto corresponderem a porcentagem de aumento igual, observa-se que houve uma aumento considerável quanto a fertirrigação uma vez que as médias dos tratamentos quando se aplicou os nutrientes via água de irrigação durante o desenvolvimento da cultura apresentou valores finais de produção de álcool e de açúcar superiores na lâmina de $75 \%$ fertirrigado, valores estes que corresponde a um aumento de 34,48; 12,76; 6,58 e 3,41\%, respectivamente para $0,25,50$ e $100 \%$ de reposição hídrica fertirrigado.

Quanto a lâmina de $75 \%$ irrigada, obtivemos aumentos equivalentes a 32,$13 ; 12,68$; 8,75 e $8,93 \%$, respectivamente para $0,25,50$ e $100 \%$ de reposição hídrica irrigado.

A lâmina de $75 \%$ fertirrigado quando comparado a 0 e $100 \%$ irrigado obtiva-se valores de aumentos equivalentes, respectivamente de 40,57 e $20,26 \%$.

Em experimento realizado por Silva et al. (2009), os rendimentos de açúcar e álcool tenderam a se elevar com o aumento dos níveis de adubação de cobertura.

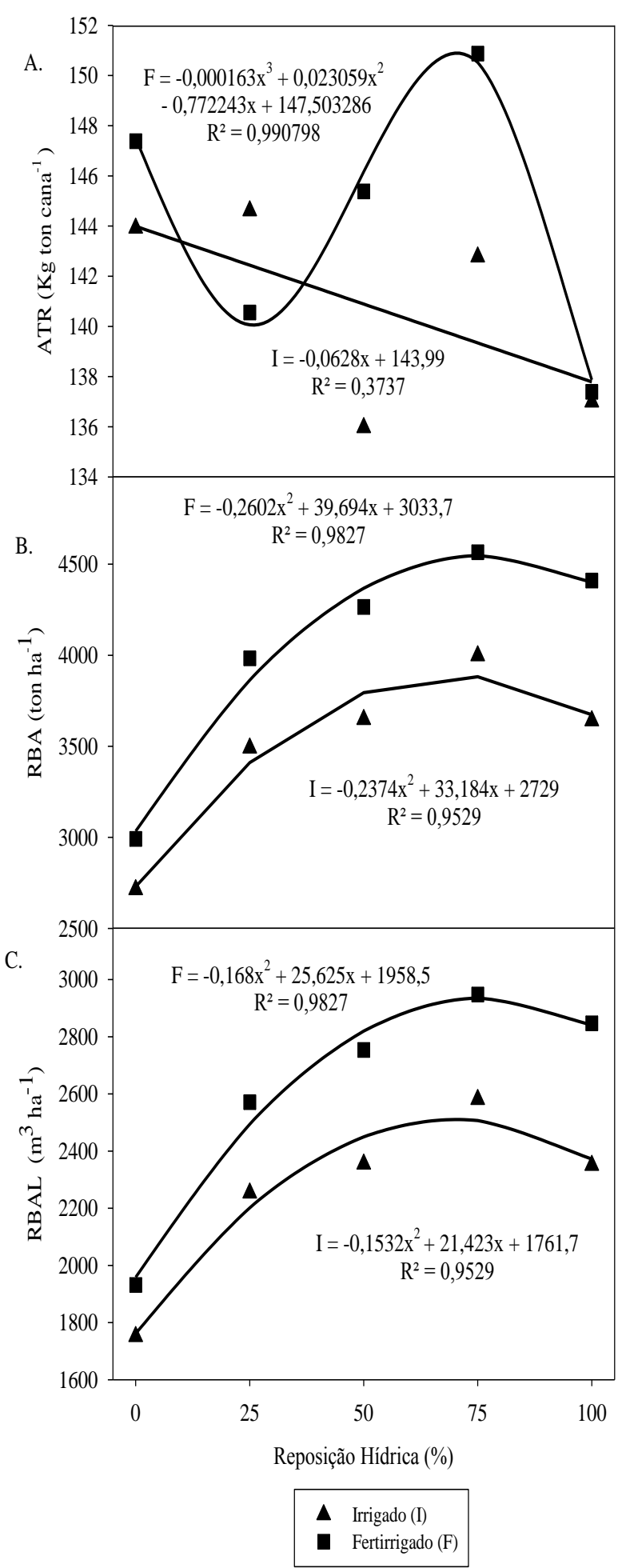

Figura 4. Características industriais (A) Açúcar total recuperável - ATR ou teor de açúcares totais (glicose, frutose e sacarose), em quilos por tonelada de cana, (B) Rendimento bruto de açúcar - RBA e (C) Rendimento bruto de álcool - RBAL da cana-deaçúcar submetida à irrigação e fertirrigação com diferentes lâminas $(0,25,50,75$ e $100 \%$ de reposição hídrica). 
De acordo com Ripoli \& Ripoli (2004), a avaliação dos indicadores de qualidade da cana, apontando um maior valor agregado à matéria-prima, deve ser feita da seguinte maneira: $\mathrm{S}$ e $\mathrm{PC}>14 \%$; $\mathrm{Q}>85 \%$; $\mathrm{AR}<$ $0,8 \% ; \mathrm{F}=11$ a $13 \% ;$ ATR $\geq 122 \mathrm{~kg} \mathrm{t}^{-1}$.

Com base nestes resultados e possível observar que o S, Q e o ATR não apresentaram em nenhum tratamento, nem mesmo quanto a $0 \%$ de reposição hídrica valores inferiores aos valores observados por estes autores, porém em relação a PC observa-se que os tratamentos com 50 e $100 \%$ irrigados, e $100 \%$ irrigado com o efeito da fertirrigação não atingiram este índice. Para o AR todos os tratamentos ficaram abaixo destes valores citados e o F apresentou somente um valor que atingiu este índice correspondente ao tratamento de $100 \%$ de reposição hídrica (somente irrigado). Moura et al. (2005) cita que a qualidade da matériaprima é definida como o conjunto de características que a cana-de-açúcar deve apresentar, atendendo às exigências da indústria, por ocasião do processamento, em especial o teor de sacarose.
A Tabela 5 mostra as características industriais da cana-de-açúcar na presença e ausência da fertirrigação com $\mathrm{N}$ e $\mathrm{K}$ sob as diferentes lâminas de irrigação.

A presença dos nutrientes $\mathrm{N}$ e $\mathrm{K}$ via água de irrigação contribuiu paras se obter um comportamento diferente em todas as lâminas de irrigação aplicadas. A cana-deaçúcar mostrou em médias gerais sempre uma maior concentração com diferença significativa para parâmetros de rendimento como em características industriais menos para AR segundo o teste Tukey a $5 \%$ de probabilidade. Da mesma forma quando analisa-se cada variável separada quanto a presença e ausência de fertirrigação (Com e Sem), observa-se que todas as variáveis de maneira geral foram estatisticamente melhores na presença de fertirrigação (Com) menos para: B em 100\%; PC em 25\%; F em 75\%; S em 25\%; Q em 25 e 100\%; ATR em 25; AR em 0, 50, 75 e $100 \%$ e RBA em $25 \%$ porém destes apresentaram médias estatisticamente iguais $0 \%$ para AR; $75 \%$ para F; $100 \%$ para PC, S, ATR e RBA. 
Tabela 5. Médias das características industriais e de rendimento quanto a presença e ausência do fator fertirrigação em todas as lâminas de irrigação utilizadas na cana-de-açúcar.

\begin{tabular}{|c|c|c|c|c|c|c|}
\hline & \multicolumn{6}{|c|}{ Tratamentos } \\
\hline \multirow{2}{*}{ Variáveis } & \multicolumn{2}{|c|}{$0 \%$} & \multicolumn{2}{|c|}{$25 \%$} & \multicolumn{2}{|c|}{$50 \%$} \\
\hline & Com & Sem & Com & Sem & Com & Sem \\
\hline B & 19.32 a & $18.69 \mathrm{~b}$ & $18.45 \mathrm{~b}$ & $18.80 \mathrm{a}$ & $19.24 \mathrm{a}$ & $18.00 \mathrm{~b}$ \\
\hline PC & $14.98 \mathrm{a}$ & $14.60 \mathrm{~b}$ & $14.23 \mathrm{~b}$ & $14.68 \mathrm{a}$ & $14.75 \mathrm{a}$ & $13.72 \mathrm{~b}$ \\
\hline $\mathbf{F}$ & $10.30 \mathrm{a}$ & $9.60 \mathrm{~b}$ & $9.90 \mathrm{a}$ & $9.800 \mathrm{~b}$ & $10.40 \mathrm{a}$ & $9.900 \mathrm{~b}$ \\
\hline $\mathbf{S}$ & $17.18 \mathrm{a}$ & $16.54 \mathrm{~b}$ & $16.23 \mathrm{~b}$ & $16.69 \mathrm{a}$ & $16.93 \mathrm{a}$ & $15.63 \mathrm{~b}$ \\
\hline $\mathbf{Q}$ & 88.90 a & $88.51 \mathrm{~b}$ & $87.94 \mathrm{~b}$ & 88.77 a & 87.99 a & $86.81 \mathrm{~b}$ \\
\hline ATR & $147.38 \mathrm{a}$ & $143.92 \mathrm{~b}$ & $140.55 \mathrm{~b}$ & $144.61 \mathrm{a}$ & $145.38 \mathrm{a}$ & $135.97 \mathrm{~b}$ \\
\hline $\mathbf{A R}$ & $0.59 \mathrm{a}$ & $0.60 \mathrm{a}$ & $0.62 \mathrm{a}$ & $0.60 \mathrm{~b}$ & $0.620 \mathrm{~b}$ & $0.660 \mathrm{a}$ \\
\hline RBA & $18.39 \mathrm{a}$ & $17.70 \mathrm{~b}$ & $17.36 \mathrm{~b}$ & $17.86 \mathrm{a}$ & $18.11 \mathrm{a}$ & $16.71 \mathrm{~b}$ \\
\hline RBAL & $1931.06 \mathrm{a}$ & $1751.50 \mathrm{~b}$ & $2571.22 \mathrm{a}$ & $2253.65 \mathrm{~b}$ & $2753.32 \mathrm{a}$ & $2354.86 \mathrm{~b}$ \\
\hline \multirow{2}{*}{ Variáveis } & \multicolumn{2}{|c|}{$75 \%$} & \multicolumn{2}{|c|}{$100 \%$} & \multicolumn{2}{|c|}{ Geral } \\
\hline & Com & Sem & Com & Sem & Com & Sem \\
\hline B & $19.42 \mathrm{a}$ & $18.75 \mathrm{~b}$ & $18.36 \mathrm{~b}$ & $18.630 \mathrm{a}$ & $18.95 \mathrm{a}$ & $18.57 \mathrm{~b}$ \\
\hline PC & $15.38 \mathrm{a}$ & $14.46 \mathrm{~b}$ & $13.88 \mathrm{a}$ & $13.82 \mathrm{a}$ & $14.64 \mathrm{a}$ & $14.25 \mathrm{~b}$ \\
\hline $\mathbf{F}$ & $9.80 \mathrm{a}$ & $9.800 \mathrm{a}$ & $11.00 \mathrm{a}$ & $10.50 \mathrm{~b}$ & $10.18 \mathrm{a}$ & $10.02 \mathrm{~b}$ \\
\hline $\mathbf{S}$ & $17.49 \mathrm{a}$ & $16.45 \mathrm{~b}$ & $15.98 \mathrm{a}$ & $16.04 \mathrm{a}$ & $16.76 \mathrm{a}$ & $16.27 \mathrm{~b}$ \\
\hline $\mathbf{Q}$ & $90.08 \mathrm{a}$ & $87.72 \mathrm{~b}$ & $16.45 \mathrm{~b}$ & $86.10 \mathrm{a}$ & $88.38 \mathrm{a}$ & $87.58 \mathrm{~b}$ \\
\hline ATR & $150.87 \mathrm{a}$ & $142.77 \mathrm{~b}$ & $137.39 \mathrm{a}$ & $136.99 \mathrm{a}$ & $144.31 \mathrm{a}$ & $140.85 \mathrm{~b}$ \\
\hline $\mathbf{A R}$ & $0.55 \mathrm{~b}$ & $0.63 \mathrm{a}$ & $0.66 \mathrm{~b}$ & $0.69 \mathrm{a}$ & $0.60 \mathrm{~b}$ & $0.63 \mathrm{a}$ \\
\hline RBA & $18.73 \mathrm{a}$ & $17.60 \mathrm{~b}$ & $17.09 \mathrm{a}$ & $17.15 \mathrm{a}$ & $17.93 \mathrm{a}$ & $17.40 \mathrm{~b}$ \\
\hline RBAL & $2947.37 \mathrm{a}$ & $2580.92 b$ & $2846.76 \mathrm{a}$ & $2350.24 b$ & $2609.94 \mathrm{a}$ & $2258.23 b$ \\
\hline
\end{tabular}

Médias seguida de mesma letra entre colunas não diferem entre si a 5\% de probabilidade pelo teste de Tukey. Brix (B) ou teor de sólidos solúveis por cento, em peso, de caldo; Pol da cana (PC) ou teor de sacarose aparente por cento, em peso, de cana; Açúcares redutores do caldo (AR) ou teor de açúcares redutores (glicose e frutose, oriundos da hidrólise da sacarose) por cento, em peso, de caldo; Fibra da cana (F) ou teor de material insolúvel em água, por cento, em peso, de cana; Pol do caldo (S) ou teor de sacarose aparente por cento, em peso, de caldo; Pureza aparente do caldo $(\mathrm{Q})$ ou porcentagem de pol do caldo em relação ao brix; Açúcar total recuperável (ATR) ou teor de açúcares totais (glicose, frutose e sacarose), em quilos por tonelada de cana; Rendimento bruto de açúcar (RBA) e rendimento bruto de álcool (RBAL).
Dalri \& Cruz (2008), obtiveram resposta significativa da irrigação por gotejamento subsuperficial, nos dois ciclos da cultura estudados, soca e a ressoca tiveram incrementos de $38,4 \%$ e $72,9 \%$ na produção de ATR, para cana soca e a ressoca, respectivamente.

Com base nestes resultados é possível observar a influência a aplicação de $\mathrm{N}$ e $\mathrm{K}$ parcelado via água de irrigação sobre cada diferentes manejos com lâminas de irrigação na cana-de-açúcar no sudoeste goiano. Um resultado favorecedor tanto ao uso da irrigação quanto do incremento da fertirrigação todos via gotejamento subsuperficial, que mostra ser uma tecnologia a ser pensada na utilização nessa região, com economia de até $25 \%$ da água a ser aplicada além de toda economia de água e energia já caracterizado por este sistema.

\section{CONCLUSÕES}

A irrigação promoveu incrementos em todas características industriais analisadas, assim como a fertirrigação proporcionou efeitos positivos na produção.

A maior qualidade da matéria prima foi observada na lâmina de $75 \%$ de irrigação com efeito da fertirrigação. 
Houve incrementos no rendimento de açúcar e álcool de 34,48\% e 12,43\% na lâmina de $75 \%$ fertirrigada quando comparado respectivamente ao menor incremento ocorrido em $0 \%$ e ao maior rendimento ocorrido na lâmina de $75 \%$ somente irrigada.

De maneira geral, nas condições estudadas, a aplicação de uma lâmina de $75 \%$ promoveu um maior aproveitamento dos nutrientes fertirrigados e consequentemente uma maior produtividade e rendimento $\mathrm{e}$ qualidade da matéria prima cana-deaçúcar.

\section{REFERÊNCIAS BIBLIOGRÁFICAS}

BARBOSA, M. H. P.; SILVEIRA, L. C. I.; MACÊDO, G. A. R.; PAES, J. M. V. Variedades melhoradas de cana-de-açúcar para Minas Gerais. Informe Agropecuário, Belo Horizonte, v.28, n.239, p.20-24, 2007.

CARVALHO, C. M.; AZEVEDO, H. M.; DANTAS NETO, J.; MELO, E. P.; SILVA, C. T. S.; GOMES FILHO, R. R. Resposta dos parâmetros tecnológicos da terceira folha da cana-de-açúcar a diferentes níveis de irrigação. Revista Brasileira de Ciências Agrárias, Recife, v.3, n.4, p. 337-342, 2008.
CESNIK, R.; MIOCQUE, J. Melhoramento da cana-de-açúcar. Brasília: Embrapa Informação Tecnológica, 2004. 307 p.

Conselho dos Produtores de Cana-de-açúcar, Açúcar, Álcool do Estado de São Paulo Consecana -. Manual de instruções. 5.ed. Piracicaba, 2006. 112p.

DALRI, A. B. CRUZ, R. L. Produtividade da cana-de-açúcar fertirrigada com $\mathrm{N}$ e $\mathrm{K}$ via gotejamento subsuperficial. Engenharia Agrícola, Jaboticabal, v.28, n.3, p.516-524, 2008.

DALRI, A. B.; CRUZ, R. L.; GARCIA, C. J. B.; DUENHAS, L. H. Irrigação por gotejamento subsuperficial na produção e qualidade da canade-açúcar. Irriga, v.13, p.1-11, 2008.

DANTAS NETO, J; FIGUEREDO, J. L. C; FARIAS, C. H. A; AZEVEDO, H. M; AZEVEDO, C. A. V. Resposta da cana-deaçúcar, primeira soca, a níveis de irrigação e adubação de cobertura. Revista Brasileira de Engenharia Agrícola e Ambiental, v.10, n.2, p.283-288, 2006.

Empresa Brasileira de Pesquisa Agropecuária Embrapa. Centro Nacional de Pesquisa de Solos. 
Sistema brasileiro de classificação de solos. Rio de Janeiro, RJ; Embrapa Solos, 2006. 306p.

Empresa de Pesquisa Energética - EPE. Balanço energético nacional: Ano base 2011, EPE: Brasília, 2012. <http://www.epe.gov.br/mercado/Documents/S \%C3\%A9rie\%20Estudos\%20de\%20Energia/201 20104_1.pdf>. 23 Out. 2013.

FARIAS, C. H. A.; FERNANDES, P. D.; GHEYI, H. R.; DANTAS NETO, J. Qualidade industrial de cana-de-açúcar sob irrigação e adubação com zinco, em Tabuleiro Costeiro paraibano. Revista Brasileira de Engenharia Agrícola e Ambiental, Campina Grande, v.13, n.4, p. 419-428, 2009.

FERREIRA, D. F. Sisvar: a computer statistical analysis system. Ciência e Agrotecnologia (UFLA), v. 35, n.6, p. 1039-1042, 2011.

FIRME, L. P. Efeito da irrigação com efluente de esgoto tratado no sistema solo- planta em

Latossolo cultivado com cana-de-açúcar Escola Superior de Agricultura Luiz de Queiroz, Piracicaba. 109p. 2007. Tese (Doutorado).

FRASSON, F. R. Utilização de sensor ótico ativo em cana-de-açúcar. Escola Superior de
Agricultura "Luiz de Queiroz", Piracicaba, 76p. 2007. Dissertação (Mestrado).

GOUVEIA NETO, C. G. Rendimento agroindustrial da cana-de-açúcar sob suplementação hídrica e parcelamento de nitrogênio. Universidade Federal de Campina Grande - Campina Grande, PB. 145p. 2012. Tese (Doutorado)

LEITE, G. H. P.; CRUSCIOL, C. A. C. SILVA, M. A.; VENTURINI FILHO, W. G. Qualidade tecnológica da cana-de-açúcar em função da aplicação de maturadores em meio de safra. Bragantia, Campinas, v.68, n.2, p.527-534, 2009.

MOURA, M. V. P. F.; FARIAS, C. H. DE A.; AZEVEDO, C. A. V. DE; DANTAS NETO, J.; AZEVEDO, H. M.; PORDEUS, R. V. Doses de adubação nitrogenada e potássica em cobertura na cultura da cana-de-açúcar, primeira soca, com e sem irrigação. Ciência e Agrotecnologia, v.29, p.753-760, 2005.

RIPOLI, T. C. C.; RIPOLI, M. L. C. Biomassa de cana-de-açúcar: colheita, energia e ambiente. Piracicaba, 2004. 302 p.

ROSSETTO, R. Maturação da cana-de-açúcar. <http://www.agencia.cnptia.embrapa.br/gestor/c 
ana-de-acucar/arvore/CONTAG01_90_221220

06154841.html>. 10 Out. 2013.

SANTOS, M. S. M. MADALENA, J. A. SOARES, L. FERREIRA, P. V. BARBOSA, G.

V. S. Repetibilidade de características agroindustriais em cana-de-açúcar. Pesq. agropec. bras., Brasília, v.39, n.4, p.301-306, 2004.

SILVA, A. B.; DANTAS NETO, J.; FARIAS, C. H. A.; AZEVEDO, C. A. V.; AZEVEDO, H. M. Rendimento e qualidade da cana-de-açúcar irrigada sob adubações de nitrogênio e potássio em cobertura. Revista Caatinga, Mossoró, v.22, n.3, p. 236-241, 2009.

SOUSA, D. M. G.; LOBATO, E. Cerrado: Correção do solo e adubação. 2.ed. Brasília, Embrapa Informação Tecnológica, 2004. $416 p$.

ÚNICA - União da Agroindústria Canavieira do Estado de São Paulo. <http://www.unica.com.br/pages/cana_origem.as p>. 15 Out. 2013.

VAN GENUCHTEN, M. T. A. Closed form equation for predicting the hydraulic conductivity of unsaturated soils. Soil Science Society of America Journal, v. 44, p. 892-898, 1980. 